\title{
Biogas Production from Poultry Wastewater using Anaerobic Digester
}

\author{
C.Marimuthu, S.Vidya, S. Diwakaran
}

\begin{abstract}
Experimental work was carried out for the production of Biogas from poultry waste water. The Poultry waste was collected from farm near Nagercoil at Kanyakumari District. Batch anaerobic digester was designed for $20 \mathrm{~L}$ capacity. The experiment was carried out for 36 days to monitor the performance. Various parameters like $\mathrm{pH}, \mathrm{TS}, \mathrm{COD}$ have checked for every 24hours. The Production of biogas was measured by water displacement method. The methane content was analyzed by gas chromatography test. Based on the experimental data, kinetics studies have done for various models like Line Weaver-Burk method, Eadie-Hofstee method, Hanes-Woolf method. The Eadie-Hofstee Method has provided better prediction than other method. These results thus indicate that, Eadie-Hofstee Method is best to identify the growth rate, substrate concentration and Limiting Substrate Concentration of the system. The sludge of the poultry wastewater and digester were characterized by SEM analysis. The imaging was done to determine the morphological structure of the sludge and to view the bacterial growth on the surface of the sludge.
\end{abstract}

Keywords : Anaerobic Digester, Biogas, Kinetic studies Poultry waste.

\section{INTRODUCTION}

Anaerobic digesters convert organic waste (agricultural waste, garbage, animal or human manure, and alternative organic waste) into energy (in the shape of biogas or electricity) [1]. The advantages that the anaerobic digestion method provides square measure waste management, energy production, and fertilizer as by product. Waste management is incredibly necessary in each urban and rural setting. Most industrial elements of the planet have already got waste management systems, although they usually may be improved with regards to environmental impact [2]. Rural areas usually lack of sanitation or reliable waste management systems, and this is often an extremely valuable service for health and environmental reasons [3]. Anaerobic digestions will offer energy to people who don't have already and will manufacture clean energy as another to carbon-intensive energy production [4].

Clean energy is gaining a lot of importance as world energy consumption grows and humans have a lot of a

Revised Manuscript Received on December 15, 2019

* Correspondence Author

C.Marimuthu*, Department of Chemical Engineering, Sethu Institute of Technology, Pulloor, Kariapatti, Virudhunagar, India. Email: marimuthupetro@gmail.com

S.Vidya, Department of Computer Science and Engineering, Kalasalingam Institute of Technology, Krishnankovil, Srivilliputhur, India. Email:

vidya.1kshm@gmail.com

S.Diwakaran, Department of Electronics and CommunicationEngineering,Kalasalingam Academy of Research and Education, Krishnankovil, Srivilliputhur, India. Email: s.diwakaran.ece@gmail.com bearing on the world climate Anaerobic digestion is a method of degradation of a substance within the absence of air. The method happens within the stomachs of animals, and also the same organic process found in nature are often replicated and controlled by engineers.

There are four major steps of anaerobic digestion, which is represented in the figure 1.

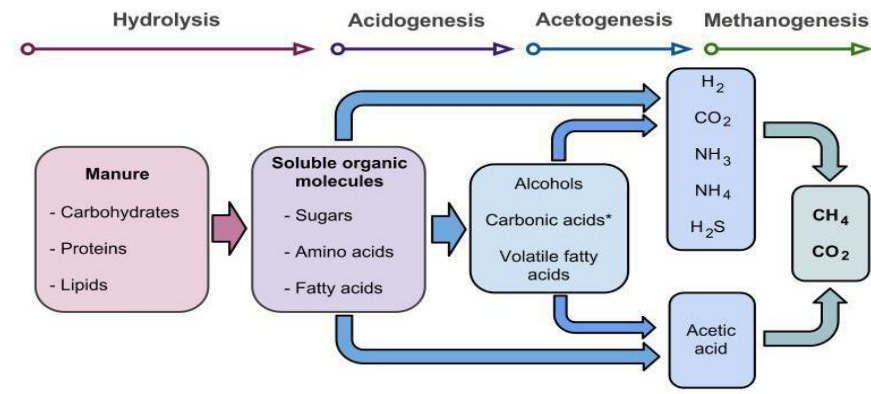

Fig 1.The anaerobic digestion pathway

The plant by-product is associate degree other profit that may add price to an anaerobic digestion system. Once a feedstock is consumed by the anaerobic digestion method, the leftover materials are often used as a soil additive to boost crop production. In rural settings, this plant by product is best used domestically or on-the-spot of the anaerobic digester $[5]$.

Biogas from anaerobic digestion usually has high amounts of sulfur that is what causes associate degree uncomfortable smell. This is often solely terribly problematic if the intent is to use the biogas in a fuel cell, as a result of the sulfur can poison the fuel cell [6-7].

Poultry waste has chosen as a feed to study the production of biogas. Experimental work has been carried out for the batch reactor to review the various factor influencing within the biogas production. Biogas production from digester is depending on the food to microorganism ration in the reactor. The survival of bacteria depends on the physical and chemical characteristics of the effluent present in the digester. [8-15].

The experimental data has been verified and find the kinetic parameter using the Line Weaver-Burk, Eadie-Hofstee and Hanes-Woolf method [16-17].

\section{MATERIALS AND METHODS}

\section{A. Raw Material Collection}

The Poultry waste was collected from farms near Nagercoil at Kanyakumari Dist. In this study Poultry waste water is taken as raw material and it's screened by the 100 mesh size and to remove the fibrous particles. It was quantitatively degraded to 
biogas with co-digested with diluted poultry manure [18].

The collected poultry waste is show in figure 2 .

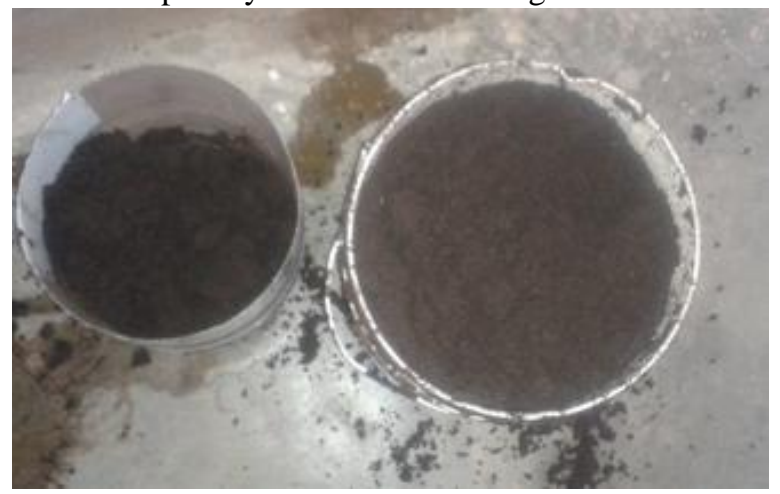

Fig 2.Poiltry Waste

\section{B. Experimental setup}

The liquid form of poultry waste is sent through the reactor and the system was started up as batch to achieve an active acidifying culture by loading the substrates. The Working volume of the bioreactor was maintained at 20 liters and run under uncontrolled $\mathrm{pH}$. The experimental was shown in figure 3 .

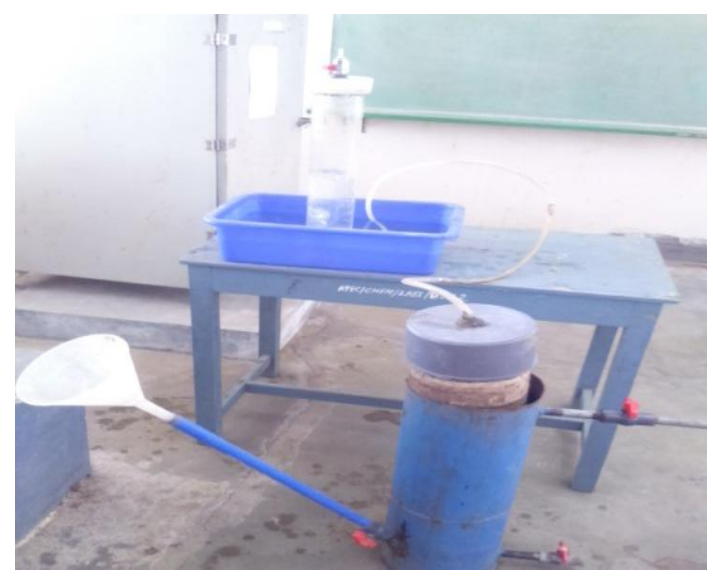

Fig 3.Experimental Setup

Experiment was carried out at atmospheric condition. After 5 days biogas yield has started from the reactor. The flowchart for biogas production is shown in the figure 4 .

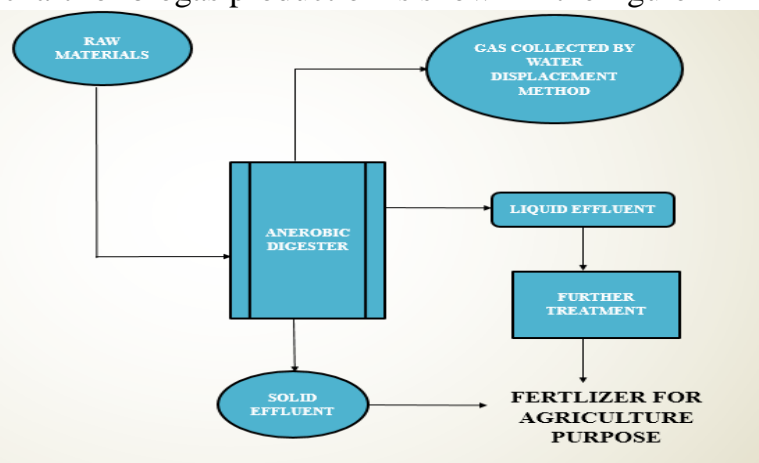

Fig 4. Flowchart of Biogas production

The biogas was collected and measured by the water displacement method. In this method the Volume of gas is stored is equal to Volume of water outlet. The Schematic diagram of experimental setup is shown in the figure 4 .

\section{RESULT AND DISCUSSION}

The digester performance for Poultry waste was investigated based on the results obtained from the experiments The Experiment was carried out at ambient temperature.

\section{A. Biogas Production}

The daily biogas production during the study period is shown in figure 5. It is measured using water displacement method. It was observed that biogas production was actually less at starting and the end of reaction. This is predicted because biogas production rate in batch condition is directly proportional to the specific growth of microorganisms. During the first 5 days of observation, there was less biogas production and mainly due to the lag of microbial growth From day 6 to 20, the biogas production was substantially increased. Maximum amount of biogas collected on day 10 and measured as $135 \mathrm{ml}$. Average of $42.06 \%$ of methane was present in the biogas This result implies that all the operation is most likely in balanced and stable operation.

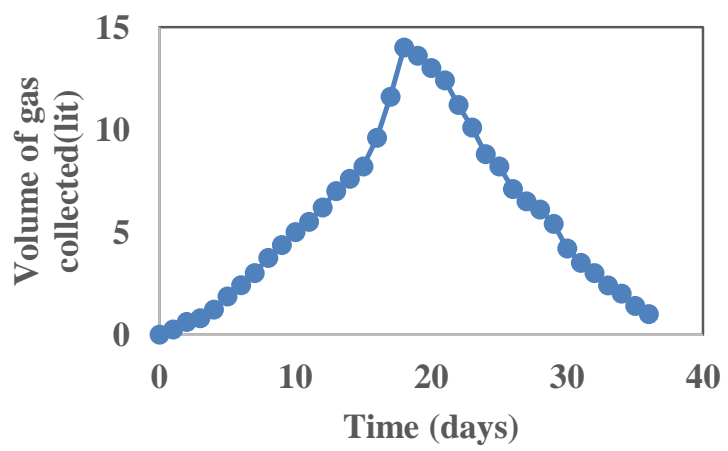

Fig 5. Daily Biogas Production

\section{B. Change of pH}

The $\mathrm{pH}$ was observed during the digester operation under stable condition. $\mathrm{pH}$ was varied from 7.2 to 5.2 during the operation. This is may be the formation of high volatile fatty acid (VFA)in the process. At the day one $\mathrm{pH}$ Value is 7.2 similarly the $\mathrm{pH}$ Value is decrease day by day. At $36^{\text {th }}$ day the $\mathrm{pH}$ Value is 5.2. The Graphical representation of $\mathrm{pH}$ values is shown in the figure 6.

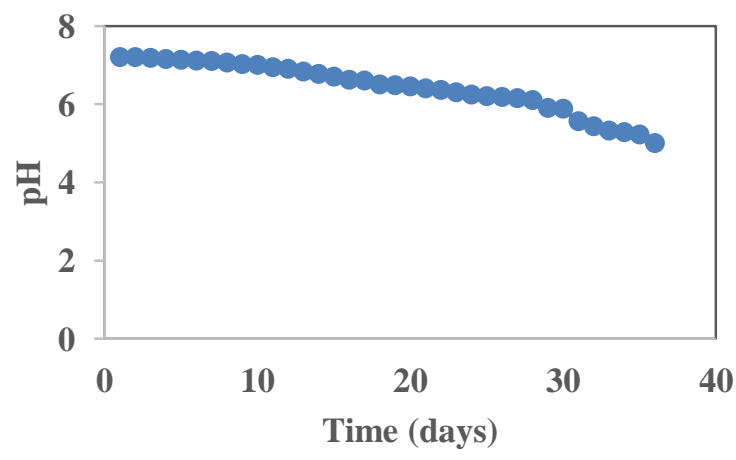

Fig. 6. Variation of $\mathrm{pH}$ during the digestion 


\section{Total Solids (TS) in Bio Reactor}

Figure 7 shows the Time (days) Vs TS profile of the reactor during the experiment. The total solid content was reduced appreciably in the digestion process. This shows that microbes has used maximum amount of substrate for the production of biogas.

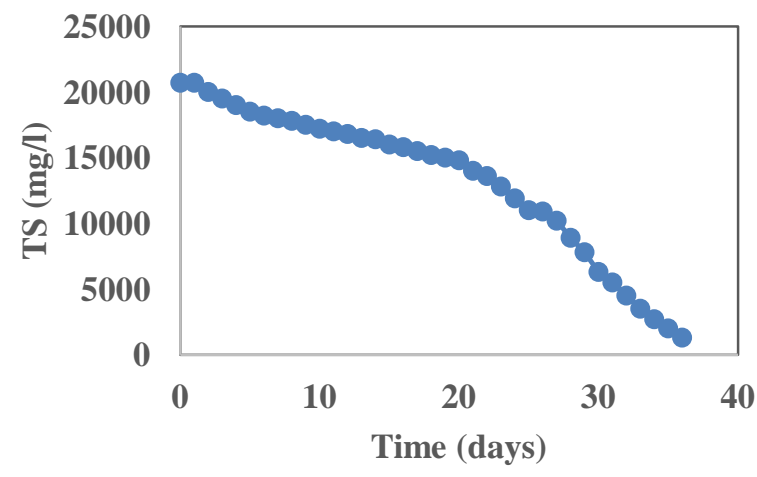

Fig 7. Variation of Total Solids during the digestion

\section{COD Degradation}

Figure 8 shows the Time (days) Vs COD profile of the bioreactor content during the experiment. COD and biogas production is directly proportional. The organic content in the reactor decrease with respect to time due to substrate utilization of microbes and simultaneous biogas production.

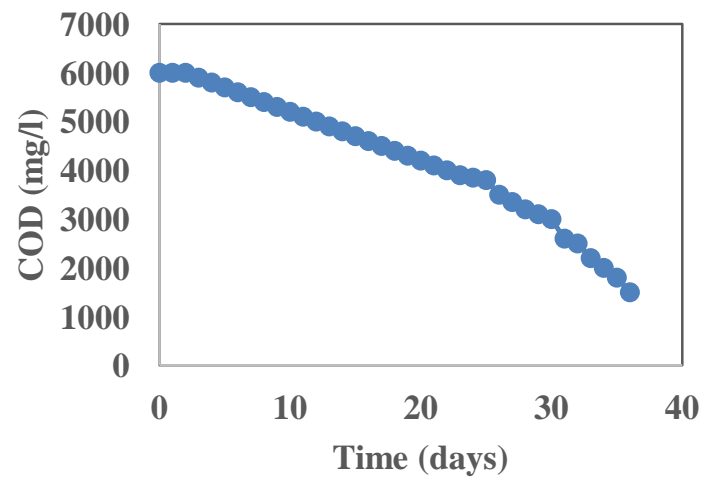

Fig 8. Reduction of COD during the digestion

\section{E. Biogas yield fraction}

The Yield fraction of Biogas Production is during the study period is shown in figure 7 . Highest biogas yield fraction was measured on the day 36 . Totally we have taken 36 days for their study period. The day by day biogas yield fraction of 36 days observation is as shown in the table. This result implies that all the operation is most likely in balanced and stable operation.

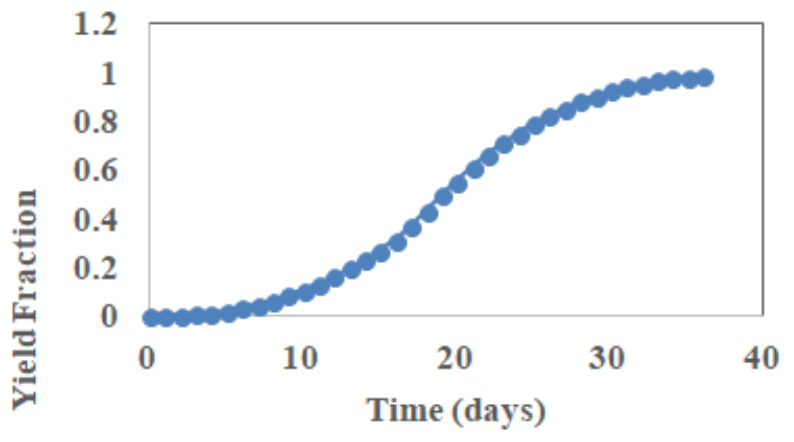

Fig 9. Biogas yield fraction during the digestion

\section{EVALUATION OF KINETIC PARAMETERS}

The evaluation of kinetic parameters basically involves the application of the transformation of Michaelis - Menten Equation (M.M.E). The transformations involve the rearrangement of M.M.E by using the best known three methods.

- The Line weaver - Burk method

- The Eadie - Hofstee Method and

- The Hanes - Woolf Method.

All the above methods help us to evaluate the Kinetic parameters

\section{A. The Line weaver- Burk Method}

This Method is also called Double reciprocal method and it is simple.

$$
r=\frac{r_{\max } C_{s}}{K_{m}+C_{s}}
$$

Where,

$r \quad=$ Specific growth rate

$\mathrm{r}_{\max }=$ Maximum Substrate Concentration.

$\mathrm{K}_{\mathrm{m}}=$ Limiting Substrate concentration.

$\mathrm{C}_{\mathrm{S}}=$ Substrate Concentration.

Writing the reciprocal for it as

$$
\begin{gathered}
\frac{1}{r}=\frac{K_{m}+C_{s}}{r_{\text {max }} C_{s}} \\
\frac{1}{r}=\frac{K_{m}}{r_{\max } C_{s}}+\frac{1}{r_{\max }}
\end{gathered}
$$

The above equation is in the form of $\mathbf{y}=\mathbf{m x}+\mathbf{c}$ So that we Plot the graph of $1 / \mathrm{r} \mathrm{Vs} 1 / \mathrm{C}_{\mathrm{S}}$

The data has been collected form experiments and plot the graph between growth rate $(1 / \mathrm{r})$ and Substrate concentration $\left(1 / C_{S}\right)$. But the graph is not Fitted the Line Weaver-Burk Method. The graphical representation of Line-weaver burk method is as shown in figure 10.

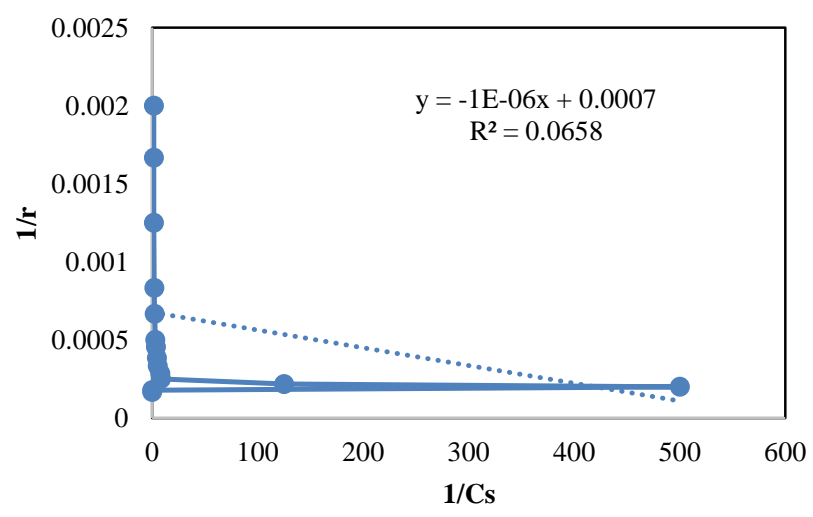

Fig 10. Plot of the Line Weaver - burk kinetic equation for anaerobic digestion

\section{B. The Eadie-Hofstee Method}

Multiplying the reciprocal of the M.M.E by $r_{\max }$ and rearranging, we get

$$
r=-\frac{K_{m} r}{c_{S}}+r_{\max }
$$

Where,

$\mathrm{r}_{\max }=$ Maximum growth rate

$\mathrm{r}=$ Specific Growth rate

$\mathrm{C}_{\mathrm{S}}=$ Substrate Concentration 
$\mathrm{K}_{\mathrm{m}}=$ Limiting Substrate concentration

Rearranging the above equation we get Specific growth rate

The data has collected from experiments and plot the graph between $\mathrm{r}$ Vs $\mathrm{r} / \mathrm{C}_{\mathrm{S}}$ to get the Slope and the intercept. The graphical representation of Eadies-Hofstee method is as shown in fig. Among these values the limiting substrate concentration $\left(\mathrm{K}_{\mathrm{m}}\right)$ and Maximum growth rate $\left(\mathrm{r}_{\max }\right)$ is to be calculated. Eadie-Hofstee Plots is representing the large errors since both Coordinate Contain $r$, but there is less bios on the points at low Substrate Concentration (Cs).

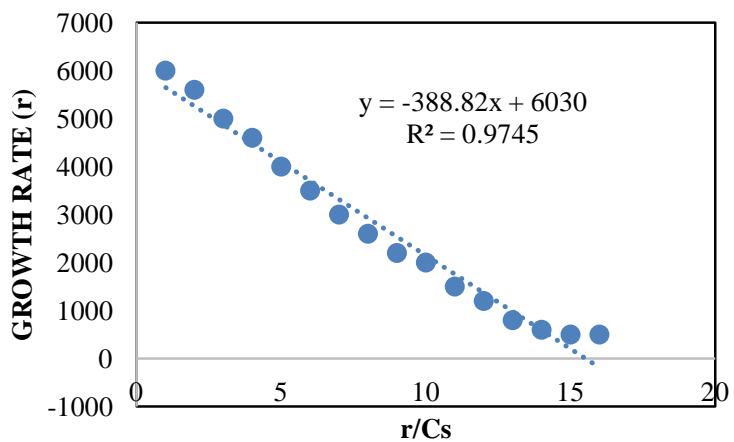

Fig 11. Plot of the Eadie - Hofstee kinetic equation for anaerobic digestion

In this method the limiting substrate concentration $\left(\mathbf{r}_{\max }=\mathbf{0 . 0 0 0 1 6 5 8 3}\right)$ has been calculated. The Experimental data is fitted in this method because the limiting substrata concentration is in negative form. This method is a modified form of Michaels-Menton's Equation.

\section{The Hanes-Woolf Method}

Consider the Michaels-Mentons equation (M.M.E),

$$
r=\frac{r_{\max } C_{s}}{K_{m}+C_{s}}
$$

Where,

$r=$ Specific Growth rate

$\mathrm{r}_{\max }=$ Maximum Growth rate

$\mathrm{K}_{\mathrm{m}}=$ Limiting Substrate Concentration

$\mathrm{C}_{\mathrm{S}}=$ Substrate Concentration.

Take the double reciprocal and multiply throughout by $\mathbf{C}_{\mathbf{S}}$ in the above equation. Such that the above equation can be written as

$$
\frac{c_{s}}{r}=\frac{K_{m}}{r_{\max }}+\frac{C_{s}}{r_{\max }}
$$

The data has collected from the experiments and plot the graph between $\mathrm{C}_{\mathrm{S}} / \mathrm{r}$ Vs $\mathrm{C}_{\mathrm{S}}$, The experimental values are taken and it is tabulated

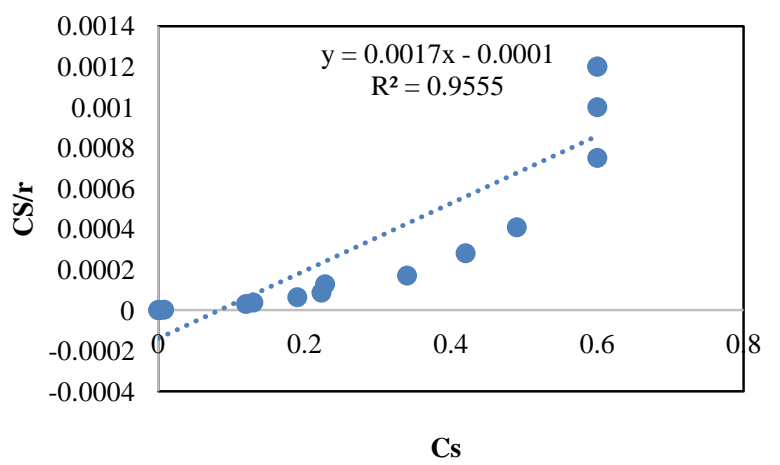

Fig 12. Plot of the Hanes-Woolf kinetic equation for anaerobic digestion ( $\mathbf{K m}=\mathbf{- 3 8 8 . 8 2})$ and the maximum growth rate

In this method the limiting substrata concentration $\left(\mathbf{K}_{\mathbf{m}}\right)$ and the maximum growth rate $\left(\mathbf{r}_{\max }\right)$ has calculated. Our Experimental data is fitted these model. So that the Kinetic parameters is easily calculated is as shown in the figure 12 .

\section{Evaluation of Kinetic Parameters}

In this study, three method such as Line weaver-burk method; Eadies-Hofstee method and Hanees-Wolf Method are evaluated by comparing the predicted and experimental results. As is shown, the predicted results using the Eadies-Hofstee Method and Hanees-Wolf method showed a good agreement with the experimental results. By using the Kinetic Equation easily identified the growth rate, substrate concentration; Limiting Substrate concentration can be calculated. Among these methods Easies-Hofstee Method got good results compared to Hanees-Wolf method. The Limiting Substrate concentration and maximum growth rate for this method is as shown in the table 1.

Table 1. Limiting Substrate concentration and maximum growth rate

\begin{tabular}{|l|l|l|l|}
\hline S.NO & Methods & $\begin{array}{l}\text { Limiting Substrate } \\
\text { concentration }\left(\mathrm{k}_{\mathrm{m}}\right) \\
\left(\mathrm{g} / \mathrm{m}^{3}\right)\end{array}$ & $\begin{array}{l}\text { Maximum growth } \\
\text { rate }\left(\mathrm{r}_{\max }\right)\left(\mathrm{g} / \mathrm{m}^{3} \mathrm{~d}\right)\end{array}$ \\
\hline 1 & $\begin{array}{l}\text { EADIES-HOFS } \\
\text { TEE }\end{array}$ & 388.82 & 0.00016583 \\
\hline
\end{tabular}

\section{SCANNING ELECTRON MICROSCOPE IMAGING}

The characterization of poultry waste sludge and the treated sludge was imaged using Scanning Electron microscope model Vega3 Tescan with a view field of $267 \mu \mathrm{m}$ before and $280 \mu \mathrm{m}$ after, width of $13.30 \mathrm{~mm}$ and range of $50 \mu \mathrm{m}$. The imaging was done to determine the morphological structure of the sludge and to view the bacterial growth on the surface of the sludge.

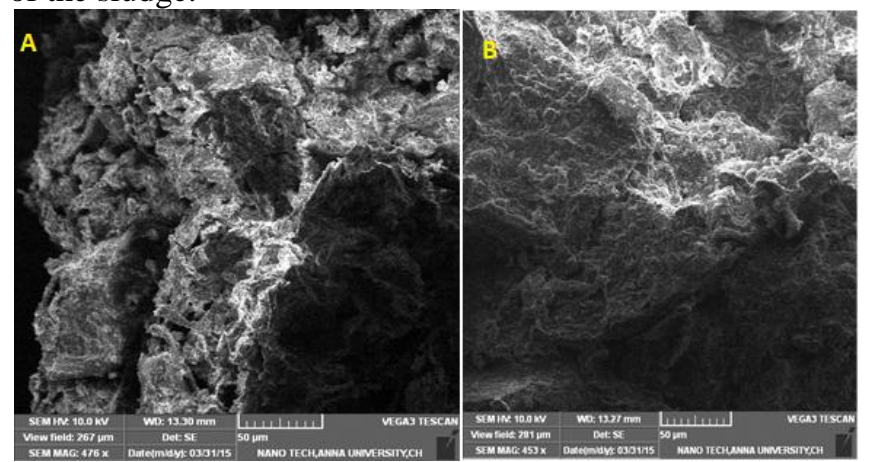

Figure 4.6: (a)SEM image of poultry waste sludge, (b) SEM image of sludge after 36days.

\section{CONCLUSION}

This study investigated the effectiveness of Poultry waste for biogas production and presented the performance characteristics of the anaerobic digestion in batch operation. Under these conditions, in batch process the COD reduced from $6000 \mathrm{mg} / \mathrm{l}$ to $1500 \mathrm{mg} / \mathrm{l}$ and 12.4 lit of biogas has produced from 20L of Poultry wastewater. The Kinetic Parameter of Line-weaver Burk Method, Eadie-Hofstee Method and Hanes-Woolf Method was studied. During the study period Line-weaver Burk 
method was not fit the experimental data and the other two methods are fitted the experimental data. Along these parameters the maximum growth rate is easily calculated. On Comparing the Eadie-Hofstee Method and Hanees-Woolf Method, The Eadie-Hofstee Method has provided better prediction than Hanees-Woolf Method with higher correlation value and generally lower deviation. The microbial growth rate of methanogenesis bacteria is to be estimated by the SEM analysis.

\section{REFERENCES}

1. Y.Jiang ,S.Heaven , C.J.Bamks.., "Strategies for stable anaerobic digestion of vegetable waste," Renewable Energy, 2012, 44, pp. 206-214.

2. Zheng-Bo Yue, Jin Wang, Xio-Meng Liu , Han-Qing Yu, "Comparison of rumen microorganism and digester sludge dominated anaerobic digesion process for aquatic plants," Renewable Energy, 2012, 46, pp. 255-258.

3. V.N.Nkemka ,M.Muto, "Two-stage anaerobic dry digestion of blue mussel and reed," Renewable Energy, 2013, 50, pp. 359-364.

4. Metcalf , Eddy, "Wastewater Engineering Treatment and Reuse," $4^{\text {th }}$ ed, TATA McGraw-Hill Ed, 2007, pp. 1005 -01017

5. Azamjeihanipour , SolmazAslanzadeh , KarthikRajendran , GopinathBalasubramanian, "High-rate biogas production from waste textiles using a two-stage process," Renewable Energy, 2013, 52, pp. 128-135.

6. Yan-Yan Ning, Shao-Feng Wang, Da-Wei Jin, Hideki Harada, Xian-Yang Shi, "Formation of hydrogen-producing granules and microbial community analysis in a UASB reactor," Renewable Energy, 2013, 53, pp. 12-17.

7. J.Havukainen ,V.Uusitalo , A.Niskanen , V.Kapustina , M.Horttanainen, "Evaluation of methods for estimating energy performance of biogas production," Renewable Energy, 2014, 66, pp. 232-240.

8. Maria M.Estevex , ZehraSapci , Roar Linjordet, John Morken, "Incorporation of fish by-product into the semi-continuous anaerobic co-digestion of pre-treated lignocellulose and cow manure, with recovery of digestate's nutrients," Renewable Energy, 2014, 66, pp. 550-558.

9. Pengchong Zhang, Che-Jen Lin, James Liu, PruekPongprueksa, Simon A. Evers, Peter Hart , "Biogas production from brown grease using a pilot-scale high-rate anaerobic digester," Renewable Energy, 2014, 68, pp. 304-313.

10. Marek Markowski, Ireneusz Bialobrzewski, Marcinzielinski, Marcin Debowski , Miroslawkrzemieniewski., "Optimizing low-temperature biogas production from biomass by anaerobic digestion," Renewable Energy, 2014, 69, pp. 219-225.

11. P.G.kougias, T.A.Kotsopoulos, G.g.Martzopoulos, "Effect of feedstock composition and organic loading rate during the mesophilic co-digestion of olive mill wastewater and swine nmanure," Renewable Energy, 2014, 69, pp. 202-207.

12. ElisavetTheofanous, NicolettaKythreotou, GregorisPanayiotou, GeorgiosFlorides, IoannisVyrides, "Energy production from piggery waste using anaerobic digestion:Current status and potential in Cyprus," Renewable Energy, 2014, 71, pp. 263-270.

13. James D.Browne, Jerry D,Murphy.," The impact of increasing organic loading in two phase digestion of food waste," Renewable Energy, 2014, 71, pp. 69-76.

14. MehranAndalib , ElsayedElbeshbishy, Nizar Mustafa, hisham Hafez , George Nakhla, Jesse Zhu., "Performance of an anaerobic fluidized bed bioreactor(AnFBR) for digestion of primary municipal wastewater treatment biosolids and bioethanol thin stillage," Renewable Energy, 2014, 71, pp. 276-285.

15. Ryan J. Lopez, Scott R Higgins, EulynPagaling, Tao Yan, Michael J.Cooney., "High rate anaerobic digestion of wastewater separated from grease trap waste," Renewable Energy, 2014, 62 pp. 234-242.

16. S.Tedesco , T.MarreroBarroso , A.G.Olabi., "Optimization of mechanical pre-treatment of Laminariaceae spp. Biomass-derived biogas," Renewable Energy, 2014, 62, pp. 527-534.

17. G.L.Karia ,R.A.Christian., Wastewater Treatment Concepts and Design Approach., $2^{\text {nd }}$ Edition, PHI Publication,
18. J. Gelegenis et al, "Optimization of biogas production by co-digesting whey with diluted poultry manure", Renewable Energy, 2007, 32. Pp. $-2147-2160$.

\section{AUTHORS PROFILE}

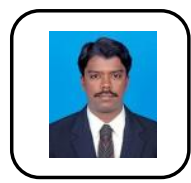

Dr.C. Marimuthu, is currently working as Associate Professor in the Department of Chemical Engineering in Sethu Institute of Technology, Kariapatti, Virudhunagar, India. His research area is biofuels and Lifecycle assessment. He has published more than 10 research papers in international journal.

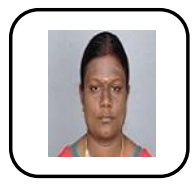

S.Vidya is currently working as Assistant professor in the Department of Computer Science and Engineering in Kalasalingam Institute of Technology, Krishnankoil, Srivilliputhur, India and pursuing Ph.d. in Anna University, Chennai. She is a $27^{\text {th }}$ rank holder in M.E. Her learning techniques. research area is wind speed forecasting using deep

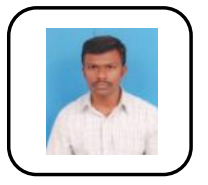

Dr. S.Diwakaran, working as Assistant Professor, Department of Electronics and Communication Engineering, Kalasalingam Academy of Research and Education. His research areas include wireless networks, Network Security, Distributed Networks and Management studies. He had published more than 6 